\title{
Distribuição dos Casos de Leishmaniose Tegumentar Americana(LTA) em Pernambuco no ano 2002
}

\author{
Valdenilson Aguiar ${ }^{1}$, Glaciene Mary da S.Goncalves ${ }^{2}$, Luciano Alves do Nascimento ${ }^{1}$, Rose \\ Mary de Aquino Gomes ${ }^{2}$.
}

\section{INTRODUÇÃO}

A Leishmaniose Tegumentar Americana (LTA) é uma infecção zoonótica não contagiosa causada por protozoários do gênero Leishmania(MS,2000), que acomete primariamente os animais silvestres e domésticos. (Marzochi,1992).É transmitida entre os animais e o homem pela picada das fêmeas de diversas espécies de flebótomos (Marzochi,1992).

As manifestações clínicas da doença se iniciam com uma pápula que tipicamente se transforma em úlcera indolor. As lesões podem ser únicas ou múltiplas e ocasionalmente, podem ser ulceradas e difusas. Podendo cicatrizar espontaneamente ao término de semanas ou meses ou persistir durante um ano ou mais(OPAS,1997).

A doença ocorre nas regiões quentes e subdesenvolvidas do Velho e Novo mundo(Marzochi,1992).Sua distribuição no continente americano é ampla, estendendo-se do sul dos EUA até o Norte da Argentina. No Brasil, é registrada em todos as regiões, com destaque para o Norte, Nordeste e Centro-Oeste(MS,2000).

Considerada anteriormente uma endemia tipicamente rural, atualmente encontra-se em expansão geográfica atingindo regiões periurbanas(MS,2000).

0 presente estudo objetiva identificar a situação atual da doença com relação a distribuição geográfica no estado de Pernambuco no ano 2002.

\section{OBJETIVOS}

\section{Geral}

Conhecer a distribuição dos casos confirmados de Leishmaniose Tegumentar Americana nas mesorregiões geográficas e municípios Pernambucanos no ano 2002.

\section{Específicos}

Identificar o número de casos confirmados de LTA por municípios de Pernambuco.

Identificar o número de casos confirmados de LTA no Estado de Pernambuco, segundo mesorregiões geográficas.

Identificar o coeficiente de detecção do Leishmaniose Tegumentar Americana por municípios de Pernambuco.

\section{METODOLOGIA}

\section{Desenho de Estudo}

0 estudo é do tipo descritivo, de corte transversal, realizado em 66 municípios do estado de Pernambuco no ano 2002.

\section{Caracterização da Àrea do Estudo - Estado de Pernambuco}

Localização: porção oriental da região Nordeste do Brasil; Clima: atlântico no leste e Semi-árido no Agreste e Sertão; Vegetação: mangue(litoral), Floresta Tropical(zona da mata),Caatinga(agreste e sertão);

População: 8.161.829 habitantes;

Número de municípios: 185;

Densidade demográfica: $80,3 \mathrm{hab} / \mathrm{km}^{2}$;

Área: $98.281 \mathrm{~km}^{2}$ (excluindo a ilha de Ferrando de Noronha);

Mesorregiões do estado de Pernambuco:

\section{Delimitação da àrea Estudo}

A área de estudo corresponde a 66 municípios no estado de Pernambuco que confirmaram casos de LTA, segundo relatórios do Sistema Nacional de Informação de Agravos Notificáveis.

\section{Variáveis do Estudo}

Município, mesorregião, casos confirmados e coeficiente de detecção.

Procedimentos realizados, processamento e análise dos dados

Definição do município como unidade de análise, sendo considerada a informação mais recente disponibilizado pelo SINANW referente ao ano 2002;

Elaboração de planilha para coleta dos dados, utilizando o software Excel 97;

1. Gerência de Atenção a doenças de veiculação hídrica e por vetores - Secretaria de Saúde/ PE. 2. Divisão de Vigilância Epidemiológica e Ambiental em Saúde FUNASA/PE. 
Coleta de dados a partir do relatório do SINANW;

Levantamento e aglutinação dos dados de casos confirmados por municípios e mesorregiões geográficas;

0 cálculo do coeficiente de detecção foi por 100.000 habitantes e utilizado dados do IBGE/2002; foi estabelecido o risco epidemiológico através de faixas de detecção baixa, média e elevada.

Os dados da divisão geopolítica de Pernambuco utilizados são da FIAM, 1998;

Inserção dos dados em mapas , utilizando o software Corel DRAW 8;

Processamento e análise dos dados através dos softwares Excel 97 e Corel DRAW 8;

\section{RESULTADOS}

0 estado de Pernambuco no ano 2002 registrou um total 605 casos confirmados de Leishmaniose Tegumentar Americana,distribuídos em 66 municípios.

Com relação ao número de casos confirmados de LTA do estado, observamos um percentual médio de $18,34 \%$ de acometimento em crianças menores de 10 anos.

Todas as mesorregiões Pernambucanas confirmaram casos da doença ano 2002, com destaque para a Mata que 304 casos, representado $50,3 \%$ do total do estado, seguida pelo Agreste com 124 casos equivalente a 20,4\%, Metropolitana com 120, correspondendo a 19,5\%, o Sertão Pernambucano registrou 54 casos com 8,9\% do total do estado e o Sertão do São Francisco com 03 casos representando $0,5 \%$.

Com referência aos coeficientes de detecção da LTA nos municípios do estado, observamos registros de elevadas taxas, como por exemplo, o município de Amaraji, pertencente a mesorregião da Mata Pernambucana, com 316 casos por 100.000 habitantes, seguido pelo município de Cortês com 299 e Triunfo com 172,5. 0 coeficiente de detecção da doença no estado no ano 2002 foi de 6,9 casos por 100.000 habitantes.

\section{CONCLUSÃO}

Após a análise dos dados e diante dos resultados encontrados, concluímos o seguinte:

Em relação a distribuição dos casos confirmados de LTA por municípios, ocorreu uma redução $6 \%$ no número total de municípios com registro de casos, quando comparado com o ano 2001.Com relação ao número total de casos confirmados por município praticamente não ocorreu variação no período 2001 a 2002. Quanto ao percentual médio de casos confirmados de LTA em crianças, esse dado sugere uma provável transmissão da doença no intra e peridomicílio.

No que se refere a distribuição dos casos confirmados por mesorregiões geográficas, os resultados confirmam ser a mesorregião da Mata historicamente de maior endemicidade no estado de Pernambuco.

Quanto ao coeficiente de detecção por município de Pernambuco, os resultados encontrados, apesar de elevados, não apresentaram mudanças significativas com relação ao ano de 2001.

Diante do quadro descrito acima e do pouco conhecimento sobre a distribuição e comportamento das espécies de vetores da LTA, torna-se necessário investimentos na área de pesquisa, visando subsídios para ações de controle eficientes.

\section{REFERÊNCIAS BIBLIOGRÁFICAS}

Brasil. Manual de Controle da Leishmaniose Tegumentar Americana. Brasília: FUNASA, 2000. 5 ed. 62 p.

Guia de Vigilância Epidemiológica. Brasília: FUNASA, 2002. 5 ed. 842 p.

Fundação de Apoio Intermunicipal do Interior de Pernambuco. FIAMMESO.TXT. Caracterização do espaço geográfico do estado de Pernambuco. Recife 01 jan. 1998.03 disquetes, 31/2pol. Word for Windows 7. 0.

Marzochi MCA. Curso Doenças Infecto- parasitárias. Leishmanioses no Brasil. Leishmanioses tegumentares .Jornal Brasileiro de Medicina,v.63, p. 82 104,1992 .

Organizacion Panamericana de la Salud. Manual para el Control da las enfermidades transmisibles. (Washington):OPS, 1997. $541 \mathrm{p}$ (informe oficial de la Asociacón Estadunidense de Salud Pública, n.564). 